\title{
An Electromagnetic Scale Model Study of the Rhinegraben Anomaly
}

\author{
V. Ramaswamy, ${ }^{1, *}$ H. W. Dosso, ${ }^{* *}$ and R. WINTER ${ }^{* * *}$ \\ * Oil and Natural Gas Commission, Nazira, Assam State, India \\ ** Department of Physics, University of Victoria, \\ Victoria, B.C., Canada \\ ***Deutsche Forschungs- und Versuchsanstalt für Luft- und \\ Raumfahrt, Forschungszentrum Obserpfaffenhofen, \\ D-8031 Oberpfaffenhofen, West Germany
}

(Received September 14, 1981 ; Revised August 10, 1982)

The behavior of time-varying geomagnetic fields in the Rhinegraben region is investigated using a laboratory scale model. The two dimensional geophysical model proposed by WINTER $(1973,1974)$, which consists of a thin sedimentary layer with nonuniform conductivity and a series of subsurface layers, is modelled in the laboratory. The study indicates good agreement between the scale model results and the field station observations. The model results have further established that the behavior of the surface geomagnetic fields observed in the Rhinegraben region is strongly influenced both by the near-surface sedimentary layer as well as by a highly conducting layer in the upper mantle.

\section{Introduction}

Laboratory analogue models have long been used for studying geophysical problems which do not yield readily to analytical or numerical solution. Laboratory scale models are extensively used to investigate problems of interest in geomagnetic depth soundings as well as in mining geophysics. The highly conducting ocean, mantle etc. and the conducting ore bodies are commonly simulated in scale models using graphite or using bodies made of metals. The highly resistive continent is usually represented by air, salt solution or by a variety of acidic solutions. A suitable combination of these materials may yield the desired conductivity contrast, but the conductivity will have an abrupt variation at the boundary. Several geophysical problems, such as sea-land or sea-island boundary which exhibit a sudden conductivity discontinuity at the interfaces have been successfully studied in scale models (e.g., Dosso, 1973; Dosso et al., 1980; NiENABER et al., 1979). On the other hand certain geological situations, such as sedimentary layers which may indicate more or less a

\footnotetext{
${ }^{1}$ The experimental work discussed in this paper was carried out while the author was at the University of Victoria as a post-doctoral fellow.
} 
continuous and gradual lateral variation in conductivity can not be modelled simply using combination of available model materials. Such a geological problem is considered in the present study.

Geomagnetic observations carried out by WINTER $(1967,1970)$ along a profile extending from Mosal valley in the west to Munich in the east and passing through the Rhine valley graben revealed anomalous behavior of the geomagnetic fields across the graben. Winter's observations showed that the ratio of the amplitude of the vertical magnetic field $\left(H_{z}\right)$ to the amplitude of the horizontal magnetic component $\left(H_{y}\right)$ had a minimum for points over the central part of the graben and had two maxima, approximately of equal magnitude, at some distance on either side of the graben. This behavior was observed for all the frequencies studied ( $0.5-6$ cycles per hour). In a subsequent work, WINTER $(1973,1974)$ proposed a two-dimensional geophysical model to explain the anomalous behavior of the $H_{z} / H_{y}$ ratio. The model consisted essentially of a thin near-surface sedimentary layer with non-uniform conductivity and a series of subsurface layers each with uniform conductivity. The conductivity of the sedimentary layer showed a continuous horizontal variation along the entire length of the profile. It varied from a value as low as $0.02 \mathrm{sm}^{-1}$ to a value as high as $0.4 \mathrm{sm}^{-1}$ spread over a distance of $300 \mathrm{~km}$.

In the present work the two-dimensional geophysical model described by WINTER (1974) has been studied using a laboratory analogue model. The sedimentary layer with its continuous horizontal variation of conductivity has been simulated in the laboratory using a graphite plate of continuously varying thickness. The subsurface layers of uniform conductivity have also been modelled. The analogue model results have brought out several features observed in the field station measurements.

\section{Description of the Models}

WINTER $(1967,1970)$ studied the behavior of time-varying geomagnetic fields near the Rhinegraben by making simultaneous observations at several stations along a profile. The profile extended from Mosel valley to Munich and was perpendicular to the strike of the graben. The profile $A^{\prime} B^{\prime}$ and the geological background are shown in Fig. 1a. In a subsequent work WINTER (1974) interpreted the observed anomalous behavior of the geomagnetic fields with the aid of two-dimensional numerical model studies. The geophysical model proposed by WINTER (1974) which fitted well with the field observations has been reproduced in Fig. 1b. The model consisted of a thin surface layer representing the sediments with non-uniform conductivity and a sequence of subsurface layers each with uniform conductivity. For the convenience of numerical model calculations WINTER (1974) assumed the sedimentary layer to have constant thickness of $5 \mathrm{~km}$ which agreed with the observed thickness of the sedimentary column in the deepest part of the Rhinegraben. The conductivity on the otherhand was allowed to vary laterally in such a way that the conductance (equal to the product of conductivity and thickness) over the central region of the graben was 2,100 Siemens. This value of the conductance is determined by the thickness of sedimentary layers (DOEBEL, 1967) and values of the electrical conductivity from borehole measurements 

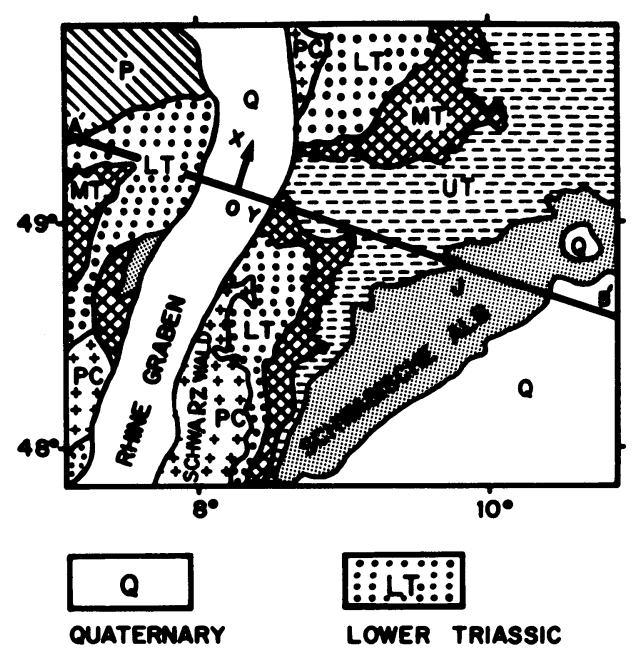

Lant:

LOWER TRIASSIC
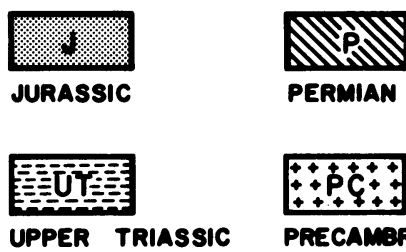

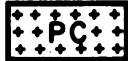

PRECAMBarian

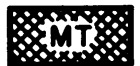

(a)

MO TRIASsIC

$Z=0 \quad k m$

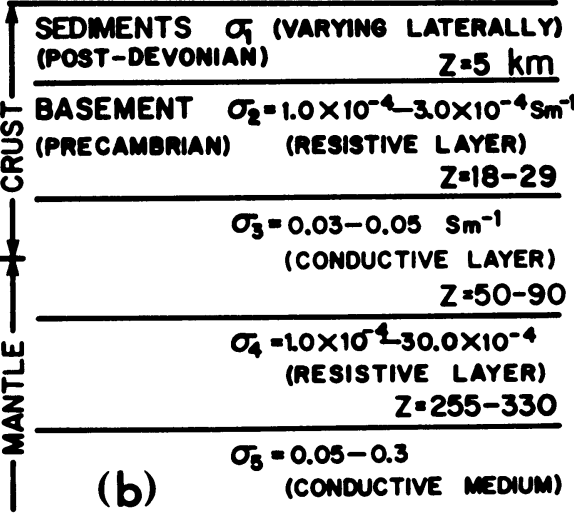

Fig. 1. (a) Profile $A^{\prime} B^{\prime}$ and the geological features of the Rhinegraben and the surroundings, (b) the two-dimensional geophysical model for the profile $\mathbf{A}^{\prime} \mathbf{B}^{\prime}$ as proposed by WINTER (1974), with the values for conductivity $\sigma$ and depth $z$ expressed in $\mathrm{sm}^{-1}$ and $\mathrm{km}$ respectively. 
(Flathe, 1967).

The model developed by WINTER (1974) for the variation of conductance of the sedimentary layer as a function of horizontal distance along the traverse $A^{\prime} \mathbf{B}^{\prime}$ is shown in Fig. 2. The spatial variation of conductance has clearly brought out two maxima, one over the center of the graben where the Quaternary deposits are exposed and a second maximum of smaller magnitude near $y \approx 68 \mathrm{~km}$ (near station $O$ ) where deposits of Upper Triassic age are exposed. It shows minima over the two flanks of the graben as well as in the Schwabische Alb (near Station He) indicating strong influence of highly resistive deposits.

The layered model shown in Fig. 1b, together with the model given in Fig. 2 for the conductance of the sedimentary layer, constitutes the geophysical model to be studied using the laboratory analogue model. The scaling conditions that must be satisfied in order that the parameters in a geophysical problem be simulated in a laboratory scale model are

$$
\begin{aligned}
& \sigma_{\mathrm{m}} L_{\mathrm{m}}=k \sigma_{\mathrm{g}} L_{\mathrm{g}}, \\
& f_{\mathrm{m}} L_{\mathrm{m}}=k^{-1} f_{\mathrm{g}} L_{\mathrm{g}},
\end{aligned}
$$

where the subscript $m$ refers to the analogue model system and the subscript $\mathrm{g}$ refers to the natural geophysical system. The parameters $\sigma, L$ and $f$ denote conductivity, length

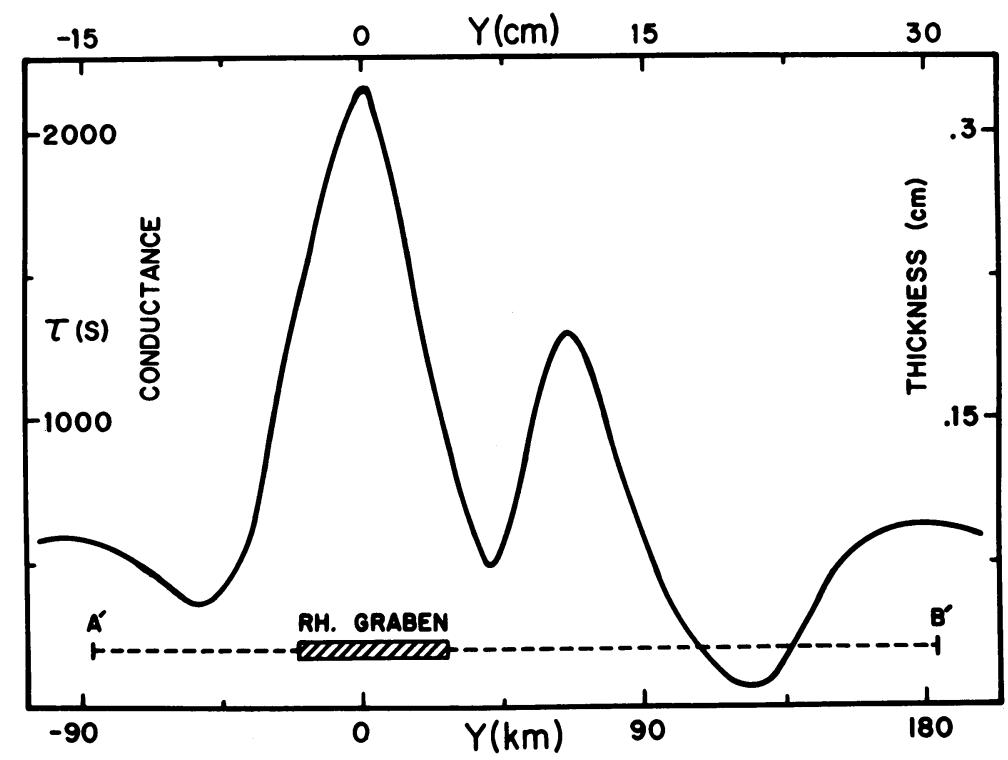

Fig. 2. The conductance of the sedimentary layer as a function of distance $Y(\mathrm{~km})$ along the profile $A^{\prime} B^{\prime}$ for the geophysical model, and the equivalent parameter, thickness, as a function of $Y(\mathrm{~cm})$ for the analogue model. 
and frequency, respectively. The parameter $k$ refers to the ratio of the geophysical impedance to the model impedance. Equation (1) is equivalent to

$$
\tau_{\mathrm{m}}=k \tau_{\mathrm{g}}
$$

where $\tau=\sigma L$ denotes conductance. Equation (3) implies that conductance in a geophysical case is directly proportional to that of the laboratory model. This suggests that, with an appropriate choice for the parameter $k$, the lateral variation of conductance for a layer of constant thickness can be simulated in the laboratory by a conducting material of constant conductivity and of varying thickness.

The laboratory model used in the present work has been described earlier (Dosso, $1966,1973)$. It consisted of a wooden tank, $2.44 \times 1.68 \times 0.76 \mathrm{~m}$ deep, containing concentrated salt solution of conductivity $21 \mathrm{sm}^{-1}$ to a depth of $63.4 \mathrm{~cm}$. A uniform inducing field was generated by means of current carrying parallel overhead wires (RAMASWAMY et al., 1975). In the model coordinate system the direction of the primary current flow was taken as the $x$-direction.

The sedimentary layer (Fig. 2) of the geophysical model was simulated in the laboratory using a graphite plate $50 \times 50 \times 0.3 \mathrm{~cm}$ thick and of conductivity 1.2 $\times 10^{5} \mathrm{sm}^{-1}$. In order to simulate the lateral variation of the conductance $\tau_{\mathrm{g}}$ (i.e., variation of $\sigma_{\mathrm{g}}$ for a constant thickness), the graphite plate was machined to obtain a lateral variation of thickness (i.e., variation of $\tau_{\mathrm{m}}$ for a constant $\sigma_{\mathrm{m}}$ ) in accordance with the scaling condition (3). For example, choosing $k=0.18$, the conductance of $2,000 \mathrm{~S}$ was scaled in the laboratory by a thickness of $0.3 \mathrm{~cm}$. Likewise a thickness of $0.075 \mathrm{~cm}$ would correspond to a geophysical conductance of $500 \mathrm{~S}$, and so on. It should be mentioned here that, since the graphite plate chosen was $0.3 \mathrm{~cm}$ thick, the maximum conductance that could be simulated using the scaling factor $k=0.18$ was $2,000 \mathrm{~S}$. This was $100 \mathrm{~S}$ less than the maximum conductance proposed in the geophysical model. Choosing a scale factor for linear dimension, $L_{\mathrm{g}} / L_{\mathrm{m}}=6 \times 10^{5}$, the plate of dimensions $50 \times 50 \mathrm{~cm}$ represented a layer of $300 \times 300 \mathrm{~km}$ in the geophysical case. The geophysical model scale for the sedimentary layer and the corresponding analogue model scale for the graphite plate are shown in Fig. 2.

Using the scale factors already chosen, $L_{\mathrm{g}} / L_{\mathrm{m}}=6 \times 10^{5}$ and $k=0.18$, it follows from Eq. (2) that the frequency would be scaled according to the relation $f_{\mathrm{m}} / f_{\mathrm{g}}=33.3$ $\times 10^{5}$. With this the geophysical frequencies used in Winter's work 1.0, 2.0,4.0 and 6.0 cycles per hour were represented in the scale model by frequencies $1.0,1.85,3.7$, and $5.56 \mathrm{kHz}$, respectively. Likewise it follows from Eq. (1) that the conductivity would be scaled according to the relation $\sigma_{\mathrm{m}} / \sigma_{\mathrm{g}}=1.08 \times 10^{5}$.

The parameters of the analogue model and the corresponding geophysical model obtained with the scaling factors for $k$, linear dimension, conductivity and frequency are presented in Fig. 3. Comparison of the geophysical model corresponding to the scale model with the model suggested by WINTER (1974), also shown in Fig. 3, indicates how accurately the two-dimensional model proposed by WINTER (1974) has been modelled in the laboratory.

The graphite plate representing the sedimentary layer was suspended at the 

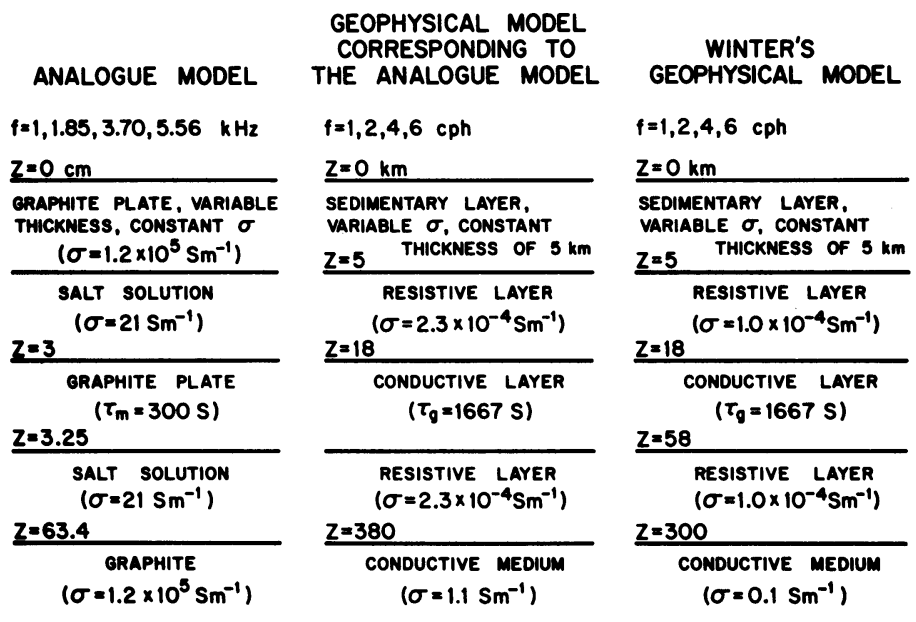

Fig. 3. The subsurface layers of the analogue model, the corresponding geophysical model and the model proposed by WINTER (1974).

surface of the salt solution with the axes of its ridges oriented along the $x$-direction ( $E$ Polarization). The two edges of the graphite plate parallel to the $y$-direction were connected to a pair of stainless steel sheets lining the tank walls. The sheets were electrically connected through a wire outside the tank, allowing the currents induced in the graphite plate to flow parallel to the source current right to the tank walls, and thereby minimizing the edge effects due to the tank walls.

The salt solution below the graphite plate represented the highly resistive basement. The conducting layer below the basement was simulated by another graphite plate $100 \times 100 \times 0.25 \mathrm{~cm}$ thick and of conductivity $1.2 \times 10^{5} \mathrm{sm}^{-1}$ suspended at a depth of $3 \mathrm{~cm}$ from the surface of the salt solution. This graphite plate would, according to the scaling factors $L_{\mathrm{g}} / L_{\mathrm{m}}=6 \times 10^{5}$ and $\sigma_{\mathrm{m}} / \sigma_{\mathrm{g}}=1.08 \times 10^{5}$, correspond to a layer $1.5 \mathrm{~km}$ thick and of conductivity $1 \mathrm{sm}^{-1}$. This would not agree with the parameters of the Winter's model which suggested a conducting layer of at least $40 \mathrm{~km}$ thick and of conductivity $0.05 \mathrm{sm}^{-1}$ below the basement. However, it should be noted that the conductance has been scaled correctly since $\tau_{\mathrm{m}}=300 \mathrm{~S}$ for the analogue model and $\tau_{\mathrm{g}}=1667 \mathrm{~S}$ for Winter's model, satisfying the scaling condition (1). This method of scaling only the conductance simply indicates that a thick layer of low conductivity of the geophysical model has been simulated in the laboratory by a thin layer of high conductivity.

\section{Discussion of Results}

The results for the $H_{z} / H_{y}$ ratio, where $H_{z}$ is the amplitude of the vertical magnetic field and $H_{y}$ is the amplitude of the horizontal magnetic field normal to the source 
current, obtained from the analogue model measurements and from the field station observations are presented in Fig. 4 for various frequencies. For convenience the model results are shown in the natural scale after taking into consideration the scaling factors. The spatial variation of conductance, $(\tau)$ of the sedimentary layer shows two broad minima and two sharp maxima. Corresponding to these minima and maxima of the conductance the $H_{z} / H_{y}$ in general undergoes maximum and minimum variations, respectively. This behavior of $H_{z} / H_{y}$ is expected on the basis of induction for a non-

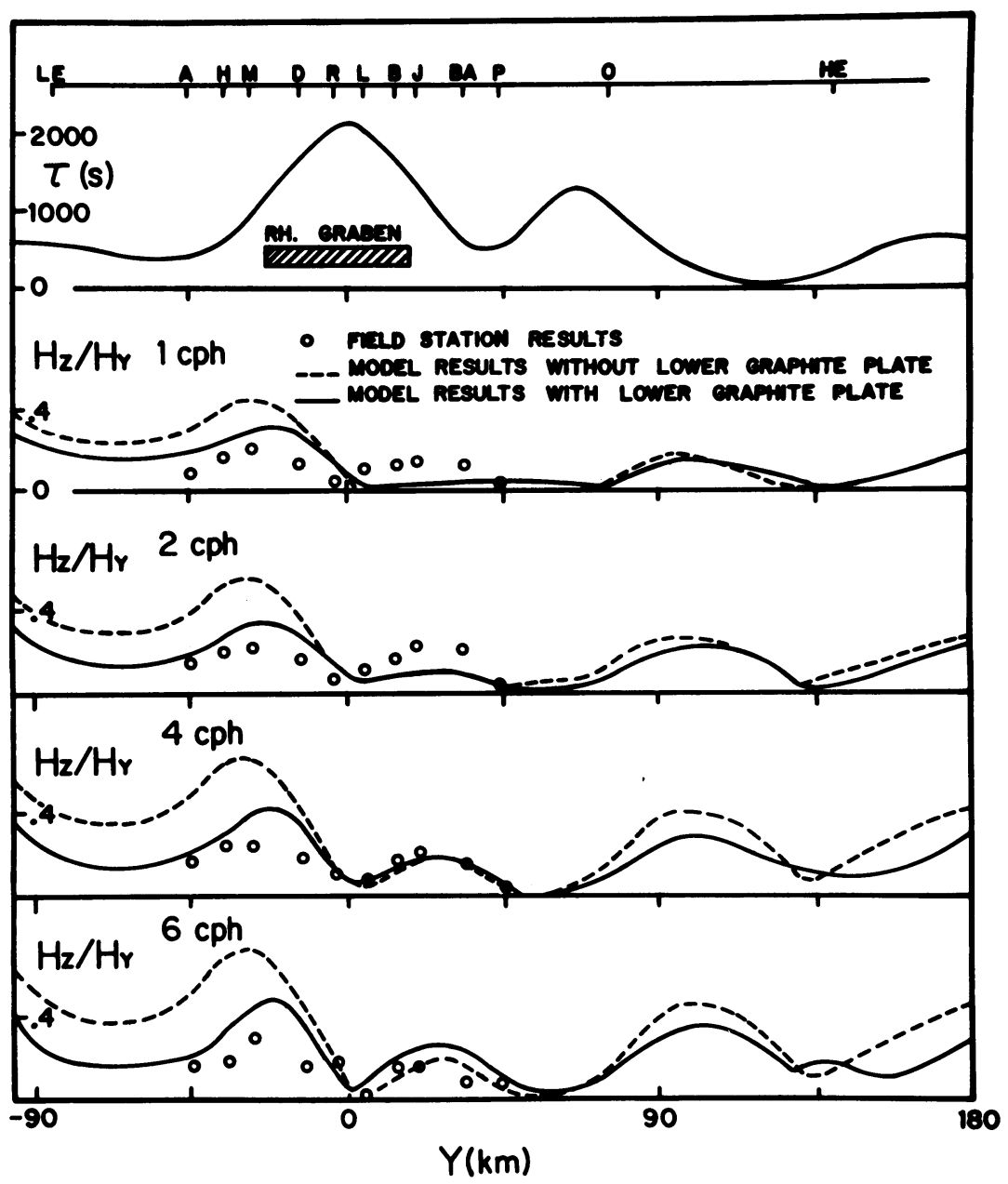

Fig. 4. Comparison of the analogue model results and the field station results for $H_{z} / H_{y}$ at the surface $z=0$ along the profile $A^{\prime} B^{\prime}$. The model results are shown for cases with and without the lower graphite plate representing the conducting layer at depth $z=18 \mathrm{~km}$. The station symbols are LE(LEI), A(ANT), H(HOR), M(MOD), D(DRE), R(RUL), L(LIN), B(BLO), J(JOH), BA(BAU), P(PIN), O(OEF), HE(HEL), used previously by WINTER (1967). 
uniform conductivity distribution by an incident plane wave. However, the location where $\tau$ has a minimum, (or maximum) and where $H_{z} / H_{y}$ has a maximum (or minimum), may not exactly coincide because of the lack of symmetry in the model. (Only for a symmetric model and source field combination is the $H_{y}$ maximum coincident with $H_{z}$ minimum giving a minimum in the ratio directly over the better conductor.)

The conductance of the sedimentary layer has a low at $y=-51 \mathrm{~km}, y=42 \mathrm{~km}$ and $y=123 \mathrm{~km}$, and a high at $y=0 \mathrm{~km}$ and $y=66 \mathrm{~km}$. Corresponding to this variation of $\tau$, the analogue model results of $H_{z} / H_{y}$ for frequencies $4 \mathrm{cph}$ and $6 \mathrm{cph}$ show enhancements near $y=-24 \mathrm{~km}, y=24 \mathrm{~km}$ and $y=120 \mathrm{~km}$, and undergo minimum variations near $y=4 \mathrm{~km}$ and $y=60 \mathrm{~km}$. The enhancement at $y=24 \mathrm{~km}$ and the low at $y=60 \mathrm{~km}$ are, however, less evident for $2 \mathrm{cph}$ and are totally absent for $1 \mathrm{cph}$. This behavior of $H_{z} / H_{y}$ for the low frequency scale model measurements may be attributed to the rate of variation, as a function of distance, of the conductance of the top graphite plate (sedimentary layer). The conductance as stated above has a low at $y$ $=42 \mathrm{~km}$ and a high at $y=66 \mathrm{~km}$. For the model frequencies $1 \mathrm{kHz}, 1.85 \mathrm{kHz}$, $3.7 \mathrm{kHz}$, and $5.56 \mathrm{kHz}$ skin depths in graphite are $4.5 \mathrm{~cm}, 3.4 \mathrm{~cm}, 2.4 \mathrm{~cm}$, and $2 \mathrm{~cm}$, respectively, which in the natural scale would correspond to $27.6 \mathrm{~km}, 20.4 \mathrm{~km}$, $14.4 \mathrm{~km}$, and $12 \mathrm{~km}$. Thus it is apparent that a horizontal separation of $24 \mathrm{~km}$ between the minima and maxima of the conductance is smaller than one skin-depth for $1 \mathrm{cph}$ (model frequency of $1 \mathrm{kHz}$ ) and is larger than one skin-depth for $2 \mathrm{cph}, 4 \mathrm{cph}$ and $6 \mathrm{cph}$. In other words, when the separation between the consecutive minimum and maximum of the conductance is less than one skin-depth the corresponding response of $H_{z} / H_{y}$ is not resolved well in the analogue model measurements. Both the model as well as the field station results indicate that the $H_{z} / H_{y}$ ratio maintains approximately the same character and magnitude for all frequencies used. From this it is obvious that the behaviour of $H_{z} / H_{y}$ at the surface is considerably influenced by the currents induced in the sedimentary layer for all the frequencies studied. This is interesting particularly when it appears that the maximum thickness of the surface graphite plate is $0.3 \mathrm{~cm}$ which is almost $1 / 15$ of the skin depth in graphite at the lowest frequency studied. Thus it appears that a conducting layer as thin as $1 / 15$ of a skin-depth could contribute to induced anomalies provided its conductance varies laterally.

Seismic surveys (MUELLER et al., 1967) show a possible association of a lowvelocity channel with an observed temperature anomaly and with that a zone of increased electrical conductivity at subcrustal depth. Magnetotelluric surveys (SCHEELKE, 1972) have suggested the existence of a highly conducting layer in the lower crust-upper mantle region under the Rhinegraben. WINTER (1974) also found it necessary to introduce a good conducting bed in the lower crust to obtain the model that fits best with his experimental data. However, some authors (see BABOUR and MosNier, 1980 and PORATH, 1971) point out that the low-frequency anomalous variations observed in Rhinegraben may not be due to currents induced in the lowercrust but may have been caused by currents induced elsewhere and channelled to the Rhinegraben sediments. In the analogue model discussed here, results obtained for a model which include a highly conducting layer in the lower crust as well as for a model 
without this conducting layer have been presented. The difference in the results for these two cases should indicate whether the currents induced in the sedimentary layer alone would be sufficient to account for the geomagnetic anomalies observed in the Rhinegraben region.

The analogue model results are shown in Fig. 4 for two cases, one with the lower graphite plate representing the highly conducting layer in the lower crustal region (solid curves) and the second without the lower graphite plate (dashed curves). The field data available for ten stations situated in the neighbourhood of the Rhinegraben are also shown in Fig. 4. It is evident from these results that the presence of the lower graphite plate not only suppresses in general the amplitude of $H_{z} / H_{y}$, but also improves the comparison between the scale model results and the field station observations for all the four frequencies studied. This suggests that the geomagnetic anomalies observed in the Rhinegraben are not fully explained by the currents induced in the sedimentary column alone, but are also strongly influenced by the currents generated in the lower crust-upper mantle region, the effect of the currents increasing with the increase in the source-frequency. The observed results for $H_{z} / H_{y}$ exhibit, more or less for all the four frequencies, a fair degree of symmetry for points on the flanks of the graben and a low at its center. Such a symmetry is not indicated in the model results for low frequency variations and this is related to the poor resolution of the induction response at the low frequency as discussed earlier. Such a phenomenon is to be expected in the field observation as well. The fact that it does not occur in the field suggests that either the second conductivity maximum east of the graben is actually related to a conductivity anomaly at depth, or that the conduction effect of PORATH (1971) may be involved.

Figure 5 shows the model and the field station results for the relative phase between the phase angles $\phi_{z}$ of the vertical magnetic field and $\phi_{y}$ of the horizontal magnetic field for a frequency of $4 \mathrm{cph}$. The phase results for other frequencies studied are similar and are not shown here. The relative phase angles were normalized by merging the observed value for $\phi_{z}-\phi_{y}$ with that obtained from the model measurements for the position $y=-45 \mathrm{~km}$ (Station ANT in Fig. 5). This value has been defined as the zero phase difference in Fig. 5. As can be seen the comparison between the two results is very good. It is interesting to note that both the results indicate rapid change in the relative phase angle near the Station PIN.

From the results discussed in this work it is evident that the analogue model results for the amplitude and phase angles of the $H_{z} / H_{y}$ field ratio generally agree with those obtained from the field station measurements in the Rhinegraben region. The scale model results in agreement with model calculations show that, for all frequencies studied, the observed geomagnetic fields at the surface can only be explained by the presence of both a highly conducting layer in the upper mantle below the Rhinegraben and lateral variation in the conductivity of the near surface sediments.

The present analogue model results do not necessarily rule out the possibility of the "conduction effect" as proposed by PORATH (1971) and later by BABOUR and MOSNIER (1980). In fact, for a low frequency, there is some discrepancy between field and model results suggesting, at least partly, the effect of low frequency "conduction" currents perturbed by the lateral conductivity variations of the sediment layer. 


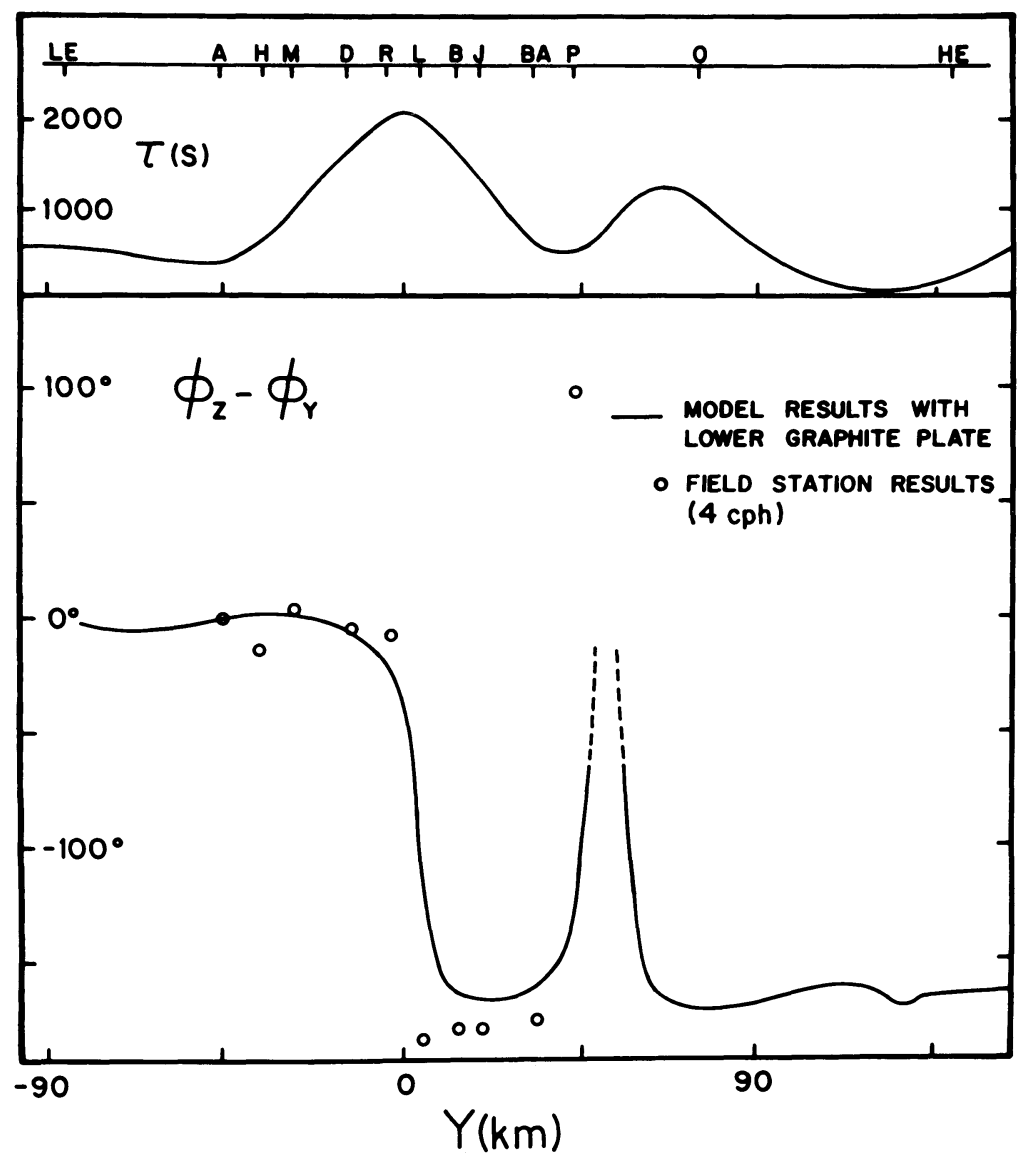

Fig. 5. Comparison of the analogue model results and the field station results for the phasedifference $\phi_{z}-\phi_{y}$ at the surface $z=0$ along the profile $A^{\prime} B^{\prime}$. The station symbols are the same as used in Fig. 4.

\section{REFERENCES}

BABour, K. and J. Mosnier, Direct determination of the characteristics of the currents responsible for the geomagnetic anomaly of the Rhinegraben, Geophys. J. R. Astr. Soc., 60, 327-331, 1980.

DOEBEL, F., The tertiary and pleistocene sediments of the northern and central part of the upper Rhinegraben, Abh. Geol. L.-Amt-Baden Wuertt., 6, 48-54, 1967.

Dosso, H. W., A plane-wave analogue model for studying electromagnetic variations, Can. J. Phys., 44, 67-80, 1966.

Dosso, H. W., A review of analogue model studies of the coast effect, Phys. Earth Planet. Inter., 7, 294-302, 1973.

Dosso, H. W., W. Nienaber, and V. R. S. Hutton, An analogue model study of electromagnetic induction in the British Isles region, Phys. Earth Planet. Inter., 22, 68-85, 1980. 
Flathe, H., The determination of the electrical resistivity of the crust within the region of the Rhinegraben, Abh. Geol. L.-Amt Baden-Wuertt., 6, 96-98, 1967.

Mueller, St., E. Peterschmitt, K. Fuchs, and J. Ansorge, The rift structure of the crust and upper mantle beneath the Rhinegraben, Abh. Geol. L.-Amt Baden-Wuertt., 6, 108, 1967.

Nienaber, W., H. W. Dosso, L. K. Law, F. W. Jones, and V. Ramaswamy, An analogue model study of electromagnetic induction in the Vancouver Island region, J. Geomag. Geoelectr., 31, 115-132, 1979.

Porath, H. Review of the evidence of low resistivity layers in the earth's crust, in The Structure and Physical Properties of the Earth's Crust, Geophysical Monograph No. 14, edited by J. G. Heacock, pp. 127-144, AGU, Washington, D.C., 1971.

Ramaswamy, V., W. Nienaber, H. W. Dosso, F. W. Jones, and L. K. LaW, Numerical and analogue model results for electromagnetic induction for an island situated near a coastline. Phys, Earth Planet. Inter., 11, 81-90, 1975.

SCHEelKe, I., Magnetotellurische Messungen im Rhinegraben und ihre Deutung mit zwei-dimensionalen Modellen, Diss. Techn. Univ. Braunschweig, 1972.

WINTER, R., Geomagnetic deep-sounding at the Rhinegraben: 1. Measurements of the magnetic variations, Abh. Geol. L.-Amt Baden Württ., 6, 127-130, 1967.

WinTER, R., Erdmagnetische Tiefensondierung im Gebiet des Oberrheingrabens: Graben Problems, Schweizerbart, Stuttgart, 1970.

WinTER, R., Der Oberrheingraben als Anomalie der eleketrischen Leitfähigkeit, untersucht mit Methoden der Erdmagnetischen Tiefensondierung, Diss. Math.-Nat Fak. Göttingen, 118 p, 1973.

WINTER, R., A model for the resistivity distribution from geomagnetic depth soundings, Approvaches to Taphrogenesis, Schweizerbart, Stuttgart, 1974. 